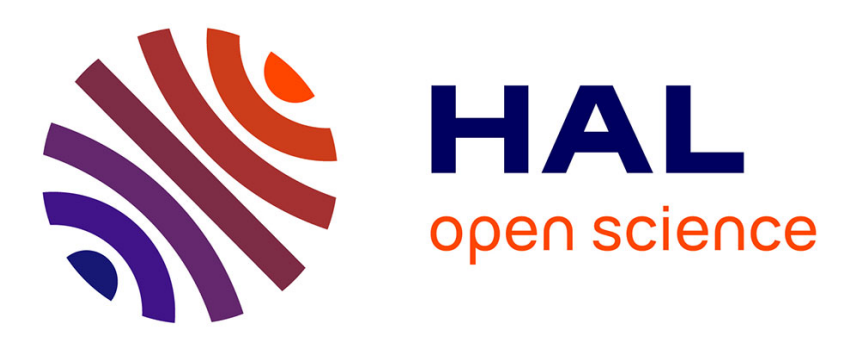

\title{
The coming-of-age of bedaquiline: a tale with an open ending
}

Lorenzo Guglielmetti, Francis Varaine

\section{To cite this version:}

Lorenzo Guglielmetti, Francis Varaine. The coming-of-age of bedaquiline: a tale with an open ending. European Respiratory Journal, 2021, 57 (6), pp.2100066. 10.1183/13993003.00066-2021 . hal03260316

\section{HAL Id: hal-03260316 https: / hal.sorbonne-universite.fr/hal-03260316}

Submitted on 14 Jun 2021

HAL is a multi-disciplinary open access archive for the deposit and dissemination of scientific research documents, whether they are published or not. The documents may come from teaching and research institutions in France or abroad, or from public or private research centers.
L'archive ouverte pluridisciplinaire HAL, est destinée au dépôt et à la diffusion de documents scientifiques de niveau recherche, publiés ou non, émanant des établissements d'enseignement et de recherche français ou étrangers, des laboratoires publics ou privés. 


\section{European Respiratory Journal}

2 Editorial

3

4 Title:

5 The coming-of-age of bedaquiline: a tale with an open ending

6

7 Word count: 1210

References: 40

8 Tables: 1 Figures: 0

9

10 Authors:

11 Lorenzo Guglielmetti, M.D., Ph.D. ${ }^{1,2,3}$

12 Francis Varaine, M.D. ${ }^{3}$

14 Affiliations:

1. Sorbonne Université, INSERM, U1135, Centre d'Immunologie et des Maladies Infectieuses, Cimi-Paris, équipe 13, Paris, France;

2. APHP, Groupe Hospitalier Universitaire Sorbonne Université, Hôpital PitiéMycobactéries aux Antituberculeux, Paris, France;

3. Médecins Sans Frontières, Paris, France.

22 Corresponding author:

23 Lorenzo Guglielmetti

24 e-mail: lorenzo.guglielmetti@aphp.fr 
Editorial on bedaquiline development

Tel: +33140779756

\section{Author contributions:}

30 LG made a substantial contribution to the conception of the manuscript, wrote the

31 manuscript, critically revised the manuscript for important intellectual content, gave final 32 approval of the current version to be published, and agrees to be accountable for all aspects

33 of the work in ensuring that questions related to the accuracy or integrity of any part of the 34 work are appropriately investigated and resolved.

35 FV made a substantial contribution to the conception of the manuscript, critically revised the manuscript for important intellectual content, gave final approval of the current version

37 to be published, and agrees to be accountable for all aspects of the work in ensuring that questions related to the accuracy or integrity of any part of the work are appropriately investigated and resolved.

\section{Financial and competing interest disclosure:}

42 LG is the co-Principal Investigator and FV is the Project Leader of two MSF-sponsored clinical

43 trials testing MDR-TB regimens including bedaquiline. They have no other competing 44 interests to disclose. There is no specific funding to declare for this study. 
TEXT:

Bedaquiline can probably be considered the biggest breakthrough of the last decades in tuberculosis drug development. The first compound of a new anti-tuberculosis drug class, diarylquinolines, bedaquiline binds the mycobacterial ATP synthase, inducing major conformational changes and ultimately impacting the bacterial respiration pathway.[1, 2] After being developed in 2005,[3] bedaquiline showed promising results in Phase II trials[4, 5], and was granted accelerated approval in 2012 by the FDA in the United States and conditional approval in 2014 by the EMA in the European Union. In the following years, the access to bedaquiline has progressively increased, from compassionate to programmatic use,[6, 7] although at an insufficient pace. Between July 2015 and December 2019, 51,098 patients received bedaquiline worldwide: although remarkable, this figure only represents $11 \%$ of those who are estimated to need it according to the most recent recommendations by the World Health Organization (WHO).[8] In this issue of the European Respiratory Journal, Chesov and co-authors elegantly describe the impact of the early years of programmatic bedaquiline implementation in the Republic of Moldova.[9]. In this retrospective cohort study, consecutive adult patients diagnosed with culture-confirmed pulmonary multidrug-resistant tuberculosis (MDR-TB) were identified through a nationwide database. Overall, 2069 MDR-TB patients were included in the study: 115 had received bedaquiline and 1954 had not. The study included patients who started treatment between 2016 and 2018, a period during which bedaquiline was reserved mainly for the most difficult-to-treat strains and for salvage treatment regimens: consequently, most bedaquiline-treated patients in the cohort have a history of treatment

67 failure, positive sputum smear results and lung cavities at baseline, and harbour fluoroquinolone-resistant strains. In order to select a comparable population, propensity 
score matching was performed by age, sex, area of residence, presence of cavitary lesion, HIV status, sputum smear positivity at baseline, fluoroquinolone resistance, previous history of tuberculosis, and drugs included in the treatment regimen: this allowed the selection of two groups of 114 patients with similar baseline characteristics. Remarkably, favourable treatment outcome rates were higher in the bedaquiline-treated group using WHO definitions (55.3\% versus $24.6 \%$ ) in all the cohort and TBnet definitions in the subgroup of patients who had at least one year post-treatment follow-up available (43.5\% versus $19.6 \%)$. In addition, mortality rates were significantly lower in the bedaquiline-treated group. Despite limitations due to its retrospective nature, missing data in some of the matching variables, and potential unknown confounders not captured by propensity scoring, this study gives an excellent example of the impact of bedaquiline as part of conventional MDRTB treatment regimens with a sound methodological approach. However, outcomes achieved by bedaquiline-treated patients in the cohort are still far from optimal, as shown by high rates of treatment failure $(27.2 \%$ and $39.2 \%$, according to WHO and TBnet definitions). This finding, similar to results from previous studies performed in the same region $[10,11]$, may have multiple explanations: bedaquiline was, in most cases $(82 \%)$, not part of the initial regimen and added subsequently to adapt to phenotypic drug susceptibility testing (DST) results; when bedaquiline was added, it was usually not accompanied by other effective drugs; bedaquiline was administered for a median of 34 weeks, and almost never for the full duration of treatment; finally, other important drugs, such as clofazimine and delamanid, were used only in few cases due to limited availability in the Republic of Moldova. 
The study by Chesov et al. adds up to an already rich body of observational evidence supporting the use of bedaquiline for MDR-TB[12]. Large, multinational cohort studies and a meta-analysis of individual patient data have confirmed the efficacy of this drug.[13-16] Similarly, initial safety concerns, in particular regarding QT interval prolongation, have been progressively dispelled.[17-20] WHO recommendations include bedaquiline among the "core drugs" of the individualized, conventional treatment regimen for MDR-TB, and recently also as part of an all-oral shorter MDR-TB regimen.[21] Moreover, latest WHO recommendations allow for increasing flexibility in establishing the duration of bedaquiline treatment beyond 24 weeks and in combining it with other QT-prolonging drugs, like delamanid.

Does this mean that the tale of bedaquiline is heading towards a happy ending? Unfortunately, we cannot say for sure (yet). All these recommendations are based on observational data, indirect comparisons (for the shorter regimen), and mostly very low quality evidence.[22] Indeed, results of a Phase III clinical trial on bedaquiline are still awaited, despite engagements by the manufacturer at the moment of provisional approval by the FDA.[23] There are also reasons of concern that should not be underestimated. In the last years, multiple reports have alerted on the selection of emerging drug resistance to bedaquiline.[24-27] Fears of increasing resistance rates have led some groups to advocate "restricting" the use of bedaquiline for fluoroquinolone-resistant strains.[28] In addition,

111 reliable DST for bedaquiline (and other new and re-purposed drugs) is currently lacking in most medium- and high-incidence countries.[29, 30]

113 Ultimately, major breakthroughs, and reliable data on the risk of acquired drug resistance, will only come from clinical research. Multiple clinical trials, summarized in the Table, are currently planned or undergoing.[31] The development path of bedaquiline is now at a 
crossroads leading to (at least) four main directions. First, bedaquiline may continue to be assessed as part of all-oral regimens for rifampicin-resistant tuberculosis: these drug combinations are tested as standardized options for all rifampicin-resistant strains (i.e. TBPRACTECAL), or as part of a strategy where regimens can be adapted to results of rapid

120 molecular testing for fluoroquinolone resistance (i.e. BEAT Tuberculosis). Second,

121 bedaquiline may be included in regimens which specifically target fluoroquinolone-

122 susceptible strains (i.e. STREAM Stage 2, endTB). Third, bedaquiline may be reserved for 123 fluoroquinolone-resistant strains, as part of combinations of new and re-purposed drugs

124 (i.e. endTB-Q). In all these cases, the overarching goal is to reduce the treatment duration of such drug-resistant strains to 6 to 10 months, while preventing the selection of drug resistance, not compromising the efficacy rates of conventional treatment, and hopefully improving its safety profile. Finally, bedaquiline may be studied as a component of new efforts to improve first-line treatment for rifampicin-susceptible tuberculosis by reducing its duration to 2 to 4 months, as hinted by promising pre-clinical[32] and bactericidal activity studies.[33] Regardless of the development path, randomized Phase III trials[34, 35], including a sufficient sample size and an internal, dynamic control arm, are needed to radically improve the evidence base for treatment of this disease.[36] Innovative trial designs may help accelerate this process, $[37,38]$ but adequate funding and strong political commitment are more critical than ever in these coronavirus disease 2019 (COVID-19) times.[39]

137 Recent improvements in MDR-TB treatment with bedaquiline-containing regimens, as shown by Chesov and co-authors,[9] are undeniable, and make a case for enhanced global access to bedaquiline and other new and re-purposed drugs. However, this may only be the 
140 beginning of the journey for bedaquiline. Strategic choices on priorities of clinical

141 development of this drug will shape its role in tuberculosis treatment in coming years. We

142 believe that these choices should be guided by the need to improve treatment outcome for

143 each patient, and that all development directions are worthy of being explored.

144 Implementation of bedaquiline-containing regimens based on high-quality evidence

145 expected from clinical trials, together with widespread DST capacity, rather than restricted

146 use for salvage therapy, may be the best way to prevent resistance and to ensure the grand

147 finale that this story deserves. 
150 Table. Selection of main ongoing and planned Phase II/III clinical trials testing bedaquiline-

\begin{tabular}{|c|c|c|c|c|c|}
\hline Trial & Phase & $\begin{array}{c}\text { Control } \\
\text { Arm }\end{array}$ & $\begin{array}{l}\text { Experimental } \\
\text { treatment } \\
\text { duration } \\
\text { (months) }\end{array}$ & $\begin{array}{l}\text { Drug used in } \\
\text { combination with } \\
\text { bedaquiline in the } \\
\text { experimental arm(s) }\end{array}$ & $\begin{array}{l}\text { Clinicaltrials.gov } \\
\text { identifier } \\
\text { (reference) }\end{array}$ \\
\hline \multicolumn{6}{|c|}{ Drug-susceptible tuberculosis } \\
\hline CRUSH-TB & 2 & Yes & 4 & Z, Mfx, Rbt or Dlm & NA \\
\hline SimpliciTB & $2 / 3$ & Yes & 4 & Z, Mfx, Ptm & NCT03338621 \\
\hline TRUNCATE-TB & 3 & Yes & $2-3$ & $H, Z, E, L z d$ & NCT03474198 \\
\hline \multicolumn{6}{|c|}{ Rifampicin-resistant tuberculosis (regardless of susceptibility to fluoroquinolones) } \\
\hline BEAT Tuberculosis & 3 & Yes & 6 & Lzd, DIm, Lfx or Cfz & NCT04062201 \\
\hline TB-PRACTECAL & $2 / 3$ & Yes & 6 & $\mathrm{Mfx}, \mathrm{Cfz}, \mathrm{Lzd}, \mathrm{Ptm}$ & NCT02589782 \\
\hline
\end{tabular}

\begin{tabular}{|c|c|c|c|c|c|}
\hline endTB & 3 & Yes & 9 & $\begin{array}{c}\mathrm{Z} \text {, Lfx or Mfx, Cfz, Lzd, } \\
\text { DIm }\end{array}$ & NCT02754765 \\
\hline STREAM Stage 2 & 3 & Yes & 9 & H, Z, E, Lfx, Cfz, Pto & NCT02409290[40] \\
\hline TB-TRUST & 3 & Yes & $6-10$ & Z, Lfx, Cs, Cfz, Lzd & NCT03867136 \\
\hline
\end{tabular}

\begin{tabular}{llllll} 
BEAT-TB & 3 & No & $6-9$ & $\mathrm{Cfz}, \mathrm{Lzd}$, DIm & NA \\
\hline endTB-Q & 3 & Yes & $6-9$ & $\mathrm{Cfz}, \mathrm{Lzd}, \mathrm{DIm}$ & NCT03896685
\end{tabular}

\begin{tabular}{ll|llll} 
ZeNIX & 3 & No & 6 & Lzd, Ptm & NCT03086486
\end{tabular}

$\mathrm{H}=$ isoniazid, $\mathrm{Rbt}=$ rifabutin, $\mathrm{Z}=$ pyrazinamide, $\mathrm{E}=$ ethambutol, $\mathrm{Lfx}=$ levofloxacin, $\mathrm{Mfx}=$ 154 moxifloxacin, $\mathrm{Cfz}=$ clofazimine, $\mathrm{Lzd}=$ linezolid, $\mathrm{DIm}=$ delamanid, $\mathrm{Ptm}=$ pretomanid, $\mathrm{NA}=$ 155 not applicable. 
Editorial on bedaquiline development

156 Acknowledgements

157 None. 


\section{References}

159

160

161

162

163

164

165

166

167

168

169

170

171

172

173

174

175

176

177

178

179

180

181

182

183

184

185

186

187

188

189

190

191

192

193

194

195

1. Guo H, Courbon GM, Bueler SA, Mai J, Liu J, Rubinstein JL. Structure of mycobacterial ATP synthase bound to the tuberculosis drug bedaquiline. Nature [Internet] 2020 [cited 2020 Dec 24]; Available from: http://www.nature.com/articles/s41586-020-3004-3.

2. Lamprecht DA, Finin PM, Rahman MdA, Cumming BM, Russell SL, Jonnala SR, Adamson $\mathrm{JH}$, Steyn AJC. Turning the respiratory flexibility of Mycobacterium tuberculosis against itself. Nat Commun 2016; 7: 12393.

3. Andries K. A Diarylquinoline Drug Active on the ATP Synthase of Mycobacterium tuberculosis. Science 2005; 307: 223-227.

4. Diacon AH, Patientia R, Krause R, Allen J, Palomino JC, Lounis N, de Beule K. The Diarylquinoline TMC207 for Multidrug-Resistant Tuberculosis. $n$ engl $j$ med 2009; : 9.

5. Diacon AH, Pym A, Grobusch MP, de los Rios JM, Gotuzzo E, Vasilyeva I, Leimane V, Andries K, Bakare N, De Marez T, Haxaire-Theeuwes M, Lounis N, Meyvisch P, De Paepe E, van Heeswijk RPG, Dannemann B. Multidrug-Resistant Tuberculosis and Culture Conversion with Bedaquiline. N Engl J Med 2014; 371: 723-732.

6. Rodriguez C, Brooks M, Guglielmetti L, Hewison C, Jachym M, Lessem E, Varaine F, Mitnick C. Barriers and facilitators to compassionate use of bedaquiline and delamanid for drug resistant tuberculosis: a mixed methods study. Public Health in Action 2018; In publication.

7. Guglielmetti L, Hewison C, Avaliani Z, Hughes J, Kiria N, Lomtadze N, Ndjeka N, Setkina S, Shabangu A, Sikhondze W, Skrahina A, Veziris N, Furin J. Examples of bedaquiline introduction for the management of multidrug-resistant tuberculosis in five countries. The International Journal of Tuberculosis and Lung Disease 2017; 21: 167-174.

8. Médecins Sans Frontières (MSF), Stop TB Partnership; 2020. Step Up for TB: TB policies in 37 countries, 4th Ed. Geneva. Available from: https://msfaccess.org/step-tb-tbpolicies-37-countries-4thed?utm_source=Twitter\&utm_medium=Organic\&utm_campaign=SUFT. Date last accessed: December 31, 2020. 2020; .

9. Chesov D, Heyckendorf J, Alexandru S, Donica A, Chesov E, Reiman M, Crudu V, Botnaru V, Lange $C$. Impact of bedaquiline on treatment outcomes of multidrugresistant tuberculosis in a high-burden country. European Respiratory Journal [Internet] European Respiratory Society; 2020 [cited 2020 Dec 27]; Available from: https://erj.ersjournals.com/content/early/2020/11/26/13993003.02544-2020.

10. Hewison C, Bastard M, Khachatryan N, Kotrikadze T, Hayrapetyan A, Avaliani Z, Kiria N, Yegiazaryan L, Chumburidze N, Kirakosyan O, Atshemyan H, Qayyum S, Lachenal N, Varaine $\mathrm{F}$, Huerga $\mathrm{H}$. Is 6 months of bedaquiline enough? Results from the compassionate use of bedaquiline in Armenia and Georgia. The International Journal of Tuberculosis and Lung Disease 2018; 22: 766-772. 
11. Bastard M, Guglielmetti L, Huerga H, Hayrapetyan A, Khachatryan N, Yegiazaryan L, Faqirzai J, Hovhannisyan L, Varaine F, Hewison C. Bedaquiline and Repurposed Drugs for Fluoroquinolone-Resistant MDR-TB: How Much Better Are They? American Journal of Respiratory and Critical Care Medicine 2018; doi: 10.1164/rccm.201801-0019LE.

12. Guglielmetti L, Chiesi S, Eimer J, Dominguez J, Masini T, Varaine F, Veziris N, Ader F, Robert J. Bedaquiline and delamanid for drug-resistant tuberculosis: a clinician's perspective. Future Microbiology 2020; 15: 779-799.

13. Franke MF, Khan $P$, Hewison $C$, Khan $U$, Huerga $H$, Seung KJ, Rich ML, Zarli K, Samieva $N$, Oyewusi L, Nair $P$, Mudassar M, Melikyan N, Lenggogeni $P$, Lecca L, Kumsa A, Khan $M$, Islam S, Hussein K, Docteur W, Chumburidze N, Berikova E, Atshemyan H, Atwood S, Alam M, Ahmed S, Bastard M, Mitnick CD. Culture Conversion in Patients Treated with Bedaquiline and/or Delamanid: A Prospective Multi-country Study. Am J Respir Crit Care Med [Internet] American Thoracic Society - AJRCCM; 2020 [cited 2020 Aug 11]; Available from: http://www.atsjournals.org/doi/10.1164/rccm.202001-01350C.

14. Borisov SE, Dheda K, Enwerem M, Romero Leyet R, D'Ambrosio L, Centis R, Sotgiu G, Tiberi S, Alffenaar J-W, Maryandyshev A, Belilovski E, Ganatra S, Skrahina A, Akkerman O, Aleksa A, Amale R, Artsukevich J, Bruchfeld J, Caminero JA, Carpena Martinez I, Codecasa L, Dalcolmo M, Denholm J, Douglas P, Duarte R, Esmail A, Fadul M, Filippov A, Davies Forsman L, Gaga $M$, et al. Effectiveness and safety of bedaquiline-containing regimens in the treatment of MDR- and XDR-TB: a multicentre study. Eur Respir J 2017; 49: 1700387.

15. Schnippel K, Ndjeka N, Maartens G, Meintjes G, Master I, Ismail N, Hughes J, Ferreira H, Padanilam X, Romero R, te Riele J, Conradie F. Effect of bedaquiline on mortality in South African patients with drug-resistant tuberculosis: a retrospective cohort study. The Lancet Respiratory Medicine 2018; 6: 699-706.

16. Ahmad N, Ahuja SD, Akkerman OW, Alffenaar J-WC, Anderson LF, Baghaei P, Bang D, Barry PM, Bastos ML, Behera D, Benedetti A, Bisson GP, Boeree MJ, Bonnet $M$, Brode SK, Brust JCM, Cai Y, Caumes E, Cegielski JP, Centis R, Chan P-C, Chan ED, Chang K-C, Charles M, Cirule A, Dalcolmo MP, D'Ambrosio L, de Vries G, Dheda K, Esmail A, et al. Treatment correlates of successful outcomes in pulmonary multidrug-resistant tuberculosis: an individual patient data meta-analysis. The Lancet 2018; 392: 821-834.

17. endTB Consortium. endTB interim analysis. http://www.endtb.org/sites/default/files/201807/endTB\%20interim\%20analysis\%20\%2813\%20July\%202018\%29.pdf 2018; .

18. Lan Z, Ahmad N, Baghaei P, Barkane L, Benedetti A, Brode SK, Brust JCM, Campbell JR, Chang VWL, Falzon D, Guglielmetti L, Isaakidis P, Kempker RR, Kipiani M, Kuksa L, Lange C, Laniado-Laborín R, Nahid P, Rodrigues D, Singla R, Udwadia ZF, Menzies D, Ahmad N, Baghaei P, Barkane L, Benedetti A, Brode S, Brust J, Campbell J, Chang V, et al. Drugassociated adverse events in the treatment of multidrug-resistant tuberculosis: an individual patient data meta-analysis. The Lancet Respiratory Medicine 2020; 8: 383394. 
19. Guglielmetti L, Tiberi S, Burman M, Kunst H, Wejse C, Togonidze T, Bothamley G, Lange C. QT prolongation and cardiac toxicity of new tuberculosis drugs in Europe: a Tuberculosis Network European Trialsgroup (TBnet) study. European Respiratory Journal 2018; 52: 1800537.

20. Dooley KE. QT effects of bedaquiline, delamanid, or both in MDR-TB patients: the DELIBERATE trial. Presented at CROI, March 4-7, 2019, in Seattle, Washington. Seattle, Washington; 2019.

21. World Health Organization. WHO consolidated guidelines on tuberculosis. Module 4, Module 4, [Internet]. 2020 [cited 2020 Dec 27].Available from: http://www.ncbi.nlm.nih.gov/books/NBK558570/.

22. Guglielmetti L, Huerga H, Khan U, Varaine F. WHO 2019 guidelines on drug-resistant tuberculosis treatment: based on evidence or expert opinion? Eur Respir J 2020; 55: 1901935.

23. FDA. Sirturo approval letter. https://www.accessdata.fda.gov/drugsatfda_docs/appletter/2012/204384Orig1s000lt r.pdf (accessed on Dec 24th, 2020) 2012; .

24. Andres S, Merker M, Heyckendorf J, Kalsdorf B, Rumetshofer R, Indra A, Hofmann-Thiel S, Hoffmann H, Lange C, Niemann S, Maurer FP. Bedaquiline-resistant Tuberculosis: Dark Clouds on the Horizon. Am J Respir Crit Care Med 2020; : rccm.201909-1819LE.

25. Veziris N, Bernard C, Guglielmetti L, Le Du D, Marigot-Outtandy D, Jaspard M, Caumes E, Lerat I, Rioux C, Yazdanpanah Y, Tiotiu A, Lemaitre N, Brossier F, Jarlier V, Robert J, Sougakoff W, Aubry A. Rapid emergence of Mycobacterium tuberculosis bedaquiline resistance: lessons to avoid repeating past errors. European Respiratory Journal https://doi.org/10.1183/13993003.01719-2016.

26. Nimmo C, Millard J, van Dorp L, Brien K, Moodley S, Wolf A, Grant AD, Padayatchi N, Pym AS, Balloux F, O'Donnell M. Population-level emergence of bedaquiline and clofazimine resistance-associated variants among patients with drug-resistant tuberculosis in southern Africa: a phenotypic and phylogenetic analysis. The Lancet Microbe 2020; 1: e165-e174.

27. Tahseen S, Van Deun A, de Jong BC, Decroo T. Second-line injectable drugs for rifampicin-resistant tuberculosis: better the devil we know? Journal of Antimicrobial Chemotherapy [Internet] 2020 [cited 2021 Jan 1]; Available from: https://doi.org/10.1093/jac/dkaa489.

28. Chiang C-Y, Trébucq A, Piubello A, Rieder HL, Schwoebel V, Van Deun A. The looming threat of bedaquiline resistance in tuberculosis. Eur Respir J 2020; 55: 2000718.

29. Tiberi S, Cabibbe AM, Tomlins J, Cirillo DM, Migliori GB. Bedaquiline Phenotypic and Genotypic Susceptibility Testing, Work in Progress! EBioMedicine 2018; 29: 11-12. 
30. Salfinger M, Migliori GB. Bedaquiline: 10 years later, the drug susceptibility testing protocol is still pending. Eur Respir J 2015; 45: 317-321.

31. Lee A, Xie YL, Barry CE, Chen RY. Current and future treatments for tuberculosis | The BMJ [Internet]. [cited 2020 Dec 12]. p. m216Available from: https://www.bmj.com/content/368/bmj.m216.full.print.

32. Kort F, Fournier Le Ray L, Chauffour A, Jarlier V, Lounis N, Andries K, Aubry A, Guglielmetti L, Veziris N. Fully weekly antituberculosis regimen: a proof-of-concept study. Eur Respir J 2020; 56.

33. Tweed CD, Dawson R, Burger DA, Conradie A, Crook AM, Mendel CM, Conradie F, Diacon AH, Ntinginya NE, Everitt DE, Haraka F, Li M, van Niekerk $\mathrm{CH}$, Okwera A, Rassool MS, Reither K, Sebe MA, Staples S, Variava E, Spigelman M. Bedaquiline, moxifloxacin, pretomanid, and pyrazinamide during the first 8 weeks of treatment of patients with drug-susceptible or drug-resistant pulmonary tuberculosis: a multicentre, open-label, partially randomised, phase $2 b$ trial. The Lancet Respiratory Medicine 2019; 7: 10481058.

34. Phillips PPJ, Mitnick CD, Neaton JD, Nahid P, Lienhardt C, Nunn AJ. Keeping phase III tuberculosis trials relevant: Adapting to a rapidly changing landscape. PLoS Med 2019; 16: e1002767.

35. Cegielski JP, Nahid P, Sotgiu G. The continued hunt for the elusive standard short regimen for treatment of multidrug-resistant tuberculosis. European Respiratory Journal [Internet] European Respiratory Society; 2020 [cited 2020 Dec 27]; 55Available from: https://erj.ersjournals.com/content/55/3/2000224.

36. Guglielmetti L, Low M, McKenna L. Challenges in TB regimen development: preserving evidentiary standards for regulatory decisions and policymaking. Expert Review of Antiinfective Therapy 2020; 18: 701-704.

37. Cellamare $M$, Milstein $M$, Ventz S, Baudin E, Trippa L, Mitnick CD. Bayesian adaptive randomization in a clinical trial to identify new regimens for MDR-TB: the endTB trial. The International Journal of Tuberculosis and Lung Disease 2016; 20: 8-12.

38. Horsburgh CR, Shea KM, Phillips $P$, LaValley M. Randomized clinical trials to identify optimal antibiotic treatment duration. Trials 2013; 14: 88.

39. Nyang'wa B-T, LaHood A, Mitnick CD, Guglielmetti L. TB Research Requires Strong Protections, Innovation, and Increased Funding in Response to COVID-19. Trials 2021; In press.

40. Moodley R, Godec TR. Short-course treatment for multidrug-resistant tuberculosis: the STREAM trials. Eur Respir Rev 2016; 25: 29-35. 